\title{
Pengembangan Situs Batu Berani dengan Menggunakan Konsep Pariwisata Berkelanjutan dan Online Marketing Campaign di Desa Botubarani
}

Muhamad Danial Suma, Intan Noviantari Manyoe*, Rohmat Setiawan Duwingik, Fikri Boften, Waode Emiria Srikandi, Fandji Marfian Program Studi Teknik Geologi, Universitas Negeri Gorontalo *Email: intan.manyoe@ung.ac.id

Received: 04 March 2021; Revised: 26 April 2021; Accepted: 28 August 2021

DOI: http://dx.doi.org/10.37905/aksara.7.3.1323-1332.2021

\begin{abstract}
Abstrak
Desa Botubarani memiliki keanekaragaman geologi yang dapat dikembangkan menjadi destinasi wisata. Melalui survei yang dilakukan tim PHP2D, Desa Botubarani memiliki potensi wisata geologi yaitu situs Batu Berani. Tujuan penulisan artikel ini adalah untuk mengidentifikasi potensi yang dapat dilakukan sebagai upaya perencanaan dan pengembangan wisata yang akan memberikan dampak terhadap peningkatan pendapatan untuk masyrakat di Desa Botubarani. Hasil yang diperoleh menunjukkan bahwa Desa Botubarani memiliki potensi geologi situs Batu Berani yang dapat dikembangkan dengan konsep pariwisata berkelanjutan. Program yang diterapkan oleh tim PHP2D membawa perubahan kondisi situs yang ada di Desa Botubarani baik dari segi infrastruktur berupa QR Qodes, papan informasi situs batuberani dan hiu paus serta peningkatan kreatifitas masyarakat dengan adanya sosialisasi pembuatan kerajinan tangan dari bahan-bahan di alam.
\end{abstract}

Kata Kunci: Geopark, Pemberdayaan Masyarakat, Geowisata, Online Marketing Campaign.

\begin{abstract}
Botubarani village has a geological diversity that can be developed into a tourist destination. Through a survey conducted by the PHP2D team, Botubarani Village has the potential for geological tourism, namely the Batu Berani site. The purpose of writing this article is to identify the potential that can be done as an effort to plan and develop tourism that will have an impact on increasing income for the community in Botubarani Village. The results obtained indicate that Botubarani Village has the geological potential of the Batu Berani site which can be developed with the concept of sustainable tourism. The program implemented by the PHP2D team brought changes to the condition of the site in Botubarani Village, both in terms of infrastructure in the form of $Q R$ Qodes, information boards on the Batu Berani site and increasing community creativity with the socialization of making handicrafts from materials in nature.

Keywords: Geopark, Community Empoweremnt, Geotourism, Online Marketing Campaign.
\end{abstract}

\section{PENDAHULUAN}

Di era modern sekarang ini istilah pariwisata menjadi perhatian khusus bagi pemerintah Indonesia, karena penyumbang devisa untuk negara atau suatu daerah 
terbesar berasal dari sektor pariwisata. Dalam pengembangannya sektor pariwisata dianggap tidak akan pernah habis jika digunakan (Krishna, 2018). Setiap destinasi wisata penting untuk memiliki keunikan yang berbeda dari destinasi lainnya. Faktor yang memiliki peran penting dalam menarik wisatawan adalah keunikan yang dimiliki oleh masing-masing destinasi wisata (Suryadana, 2015).

Sektor pariwisata

Provinsi Gorontalo memiliki potensi alam, hayati dan kultural yang dapat dikembangkan menjadi destinasi wisata (Khrisna, 2018; Manyoe dkk, 2021). Potensi yang dimiliki oleh suatu daerah memegang peranan penting dalam pengembangan wisata di daerah tersebut. Suatu daerah layak dikembangkan menjadi destinasi wisata bila memiliki banyak potensi wisata.

Desa Botubarani adalah desa wisata di Provinsi Gorontalo yang memiliki keunikan wisata bahari yang dikenal oleh masyarakat saat ini, yaitu wisata Hiu Paus (Whale Shark). Desa ini juga memiliki potensi geowisata yang dapat dikemas menjadi objek wisata baru. Geowisata merupakan suatu bentuk wisata alam yang menawarkan kenampakan geologi sehingga wisatawan memiliki pemahaman akan lingkungan, pemahaman budaya fan kearifan lokal suatu wialayah (Hermawan, 2017).

Situs Batu Berani merupakan situs batuan bersejarah yang mengandung unsur geomitologi (geologi dan mitologi) tempat pendahulu desa menyimpan mayat-mayat bajak laut yang mengganggu kelangsungan hidup masyarakat desa zaman dulu. Saat ini kekayaan geologi tersebut belum mampu dimanfaatkan secara optimal karena kurangnya pemahaman masyarakat mengenai pengelolaan pariwisata berkelanjutan melalui geowisata.

Pariwisata berkelanjutan adalah konsep pengelolaan wisata yang bertanggung jawab untuk kelangsungan lingkungan maupun ekonomi masyarakat. Pariwisata berkelanjutan bertujuan agar sumber daya alam dan sumber daya manusia dapat digunakan dalam jangka waktu panjang (Sharpley, 2000). Online marketing campaign adalah bentuk promosi geowisata Desa Botubarani dengan memanfaatkan teknologi informasi agar destinasi wisata dapat terus memiliki eksistensi (Pradiatiningtyas, 2014). Untuk itu perlu adanya konsep baru yang akan diterapkan dalam pengembangan situs Batu Berani yaitu konsep berbasis pariwisata berkelanjutan dan online marketing campaign.

\section{METODE}

Kegiatan Program Holistik dan Pemberdayaan Desa (PHP2D) dilaksanakan pada bulan Juli sampai Desember 2020. Salah satu fokus utama kegiatan PHP2D adalah pengembangan Situs Batu Berani yang terletak di Desa Botubarani, Kecamatan Kabila Bone, Kabupaten Bone Bolango (Gambar 1). 


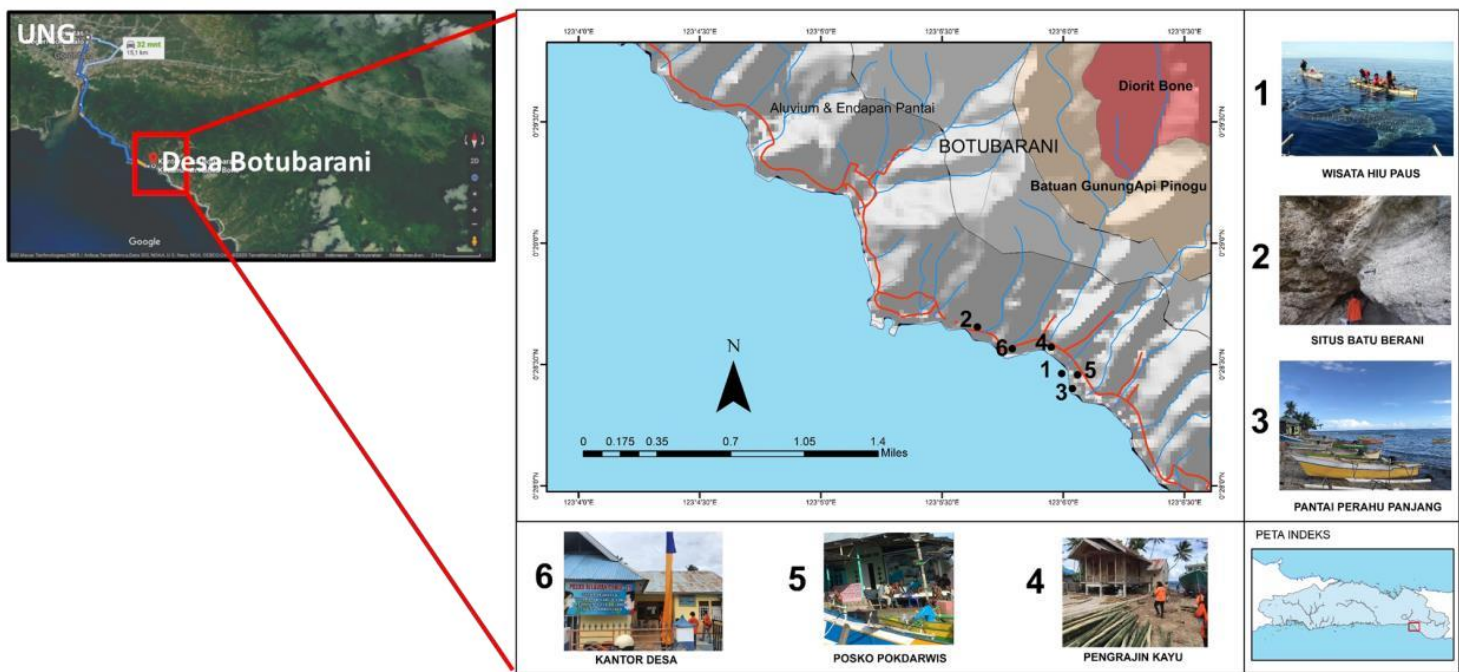

Gambar 1. Peta lokasi daerah dan titik-titik lokasi administrasi desa serta potensi wisata.

Metode pelaksanaan pengembangan Situs Batu Berani sepenuhnya dilakukan di lapangan, hal ini berdasarkan laporan Gugus Tugas Covid-19 Provinsi Gorontalo Desa Botubarani masuk ke dalam zona hijau. Adapun metode yang digunakan untuk mengatasi masalah pada mitra adalah:

1) Perencanaan

Tim PHP2D mengidentifikasi permasalahan yang ada di Desa Botubarani dan mengkomunikasikan segala hal mengenai pelaksanaan baik berupa administrasi dan konsep pelaksanaan.

2) Sosialisasi

Program Sosialisasi dilakukan untuk memberikan informasi program kepada mitra. Tim pengusul menjelaskan latar belakang program PHP2D, selain itu juga mengadakan sosialisasi mengenai pariwisata berkelanjutan dan konsep eco geowisata, kemudian merancang peralatan dan jenis pelatihan serta pendampingan yang dibutuhkan mitra untuk mencapai target yang diinginkan. Sebagai bentuk timbal balik, mitra memberikan wadah sosialisasi. Serangkaian kegiatan dilakukan berdampingan dengan mitra sebagai wujud partisipasi mitra dalam kegiatan.

3) Pelaksanaan

Pada tahap ini, tim PHP2D Bersama mitra (Karang Taruna) meperindah Kawasan situs Batu berani dari sampah yang dibuang ke situs, hal ini karena kurangnya pemahaman masyarakat mengenai aset Geowisata. Selain itu, tim PHP2D Bersama mitra membuat infrastruktur lain untuk menambah daya tarik dari situs Batu berani seperti QR Qodes, papan informasi, pagar situs

4) Workshop dan Pelatihan

Workshop dilakukan untuk menambah pengetahuan dan pemahaman mitra mengenai keterkaitan antara pengaruh pemasaran melalui media social untuk pengembangan wisata yang berkelanjutan. Pelatihan penggunaan media social dilakukan untuk meningkatkan kemampuan mitra dalam mengelola website desa dan cara pemasaran melalui media sosial. 


\section{5) Mentoring}

Tim PHP2D mendampingi para mitra yakni karang taruna dalam mengelola social media. Pendampingan dilakukan hingga mitra dapat melaksanakannya secara mandiri. Pendampingan dilakukan dengan cara mengawasi penerapan keterampilan yang diberikan untuk memastikan bahwa keterampilan yang diberikan benar-benar diterapkan di lapangan.

Dampak ekonomi yang diharapkan dari kegiatan ini yaitu berkembangnya daya Tarik objek wisata situs batuberani dengan adanya penjualan geoproduct dan pada akhirnya akan meningkatkan pendapatan masyarakat botubarani. Terkait dampaknya pada bidang sosial, kegiatan ini dapat meningkatkan kesejahteraan masyarakat melalui pembukaan lapangan kerja. Selain dampak sosial, sektor budaya juga berdampak pada berkembangnya industri kreatif batik menjadi penggerak sektor pariwisata budaya di Botubarani. Dampak bagi ilmu pengetahuan dan teknologi adalah terjadinya transfer of knowledge (transfer teknologi) antara perguruan tinggi dan masyarakat.

\section{HASIL DAN PEMBAHASAN}

Program pengabdian masyarakat mengenai pengembangan situs batuberani berbasis pariwisata yang berkelanjutan dan online marketing campaign telah dilaksanakan di Dusun 1 Tamboo Barat, Desa Botubarani Kecamatan Kabila Bone. Pengabdian kepada Masyarakat ini dilaksanakan dengan melakukan sub program lainnya antara lain sosialisasi program kepada mitra, pelatihan online marketing campaign, pembuatan infrastruktur geowisata. Pelatihan online marketing ini sebagai penggerak yang diharapkan dapat menjadi roda promosi wisata di Desa Botubarani. Adapun beberapa tahapan yang dilakukan tim PHP2D dalam pemberdayaan masyarakat dalam mengembangkan situs Batu Berani diantaranya:

1) Tahap Perencanaan

Adapun awal perencanaan kegiatan ini, tim pengabdian telah berkomunikasi dengan Kepala Desa, ketua karang taruna dan ketua Kelompok Sadar Wisata (POKDARWIS) setempat untuk membicarakan kesediaan sebagai mitra dalam program PHP2D dan mengidentifikasi berbagai permasalahan yang dihadapi mitra dalam pengembangan wisata di Desa. Melalui wawancara terbatas dengan Kepala Desa Botubarani bapak Irwan Lakoro, S.Ag., M.Si dan hasil survei lokasi terdapat potensi wisata lainnya seperti situs Batu Berani yang sampai saat ini belum dimanfaatkan karena kurangnya pemahaman dalam mengelola wisata yang mengandung unsur geologi dan mitologi (geomitologi). Tim PHP2D juga melihat belum adanya infrastruktur wisata yang memadai, belum tertatanya lokasi wisata dengan baik, aktivitas masyarakat di sekitar Batu Berani yang berpotensi mengotori dan merusak situs serta tidak adanya promosi wisata. 


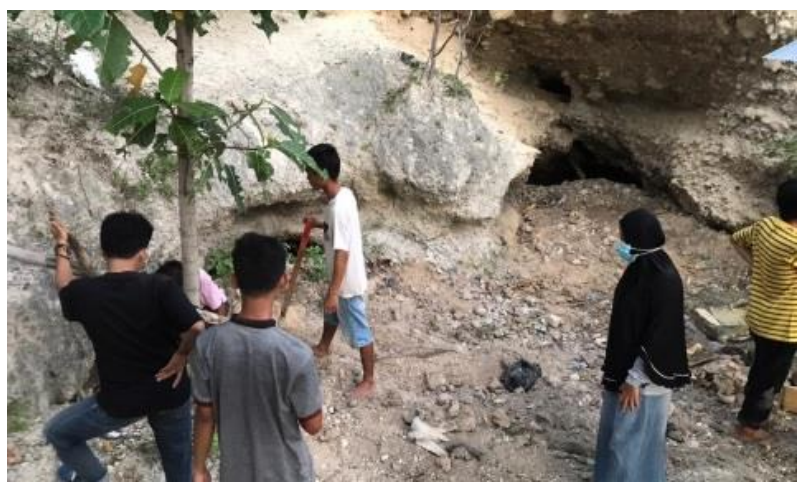

Gambar 2. Survey lokasi oleh tim PHP2D di Situs Batu Berani bersama masyarakat Desa Botubarani.

Selanjutnya atas instuksi kepala Desa Botubarani tim pengabdian bersama ketua pemuda Karang Taruna, berkolaborasi untuk mengembangkan situs Batu Berani yang memiliki potensi daya tarik wisata geomitologi.

2) Sosialisasi

a. Sosialisasi Program untuk Mitra

Tim pelaksana program pengabdian telah mensosialisasikan ketiga mitra tersebut. Lokasi sosialisasi berlangsung di kantor Desa Botubarani. Kegiatan sosialisasi diisi dengan pemaparan program yang akan dibawakan oleh tim PHP2D. Kemudian dilanjutkan dengan diskusi bersama mengenai rencana yang akan dilakukan untuk merealisasikan program yang akan dilaksanakan. Mitra tampak sangat antusias dan kooperatif selama kegiatan sosialisasi berlangsung. Hal ini terlihat dari beberapa pertanyaan, masukan dan saran yang disampaikan oleh anggota mitra kepada tim pelaksana program.

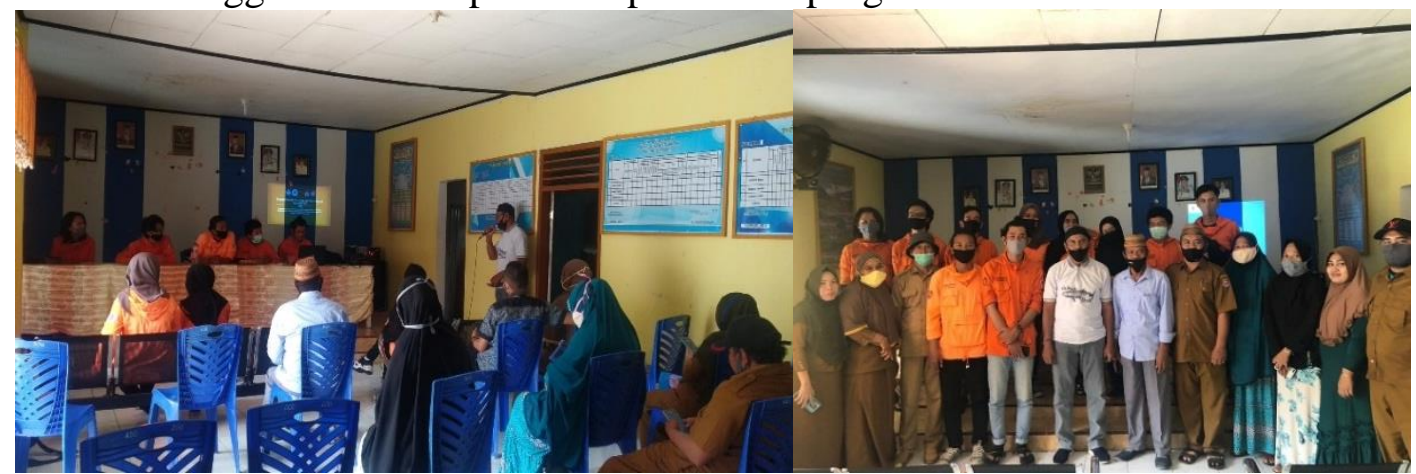

Gambar 3. Sosialisasi mengenai program tim PHP2D.

b. Sosialisasi Konsep Pariwisata Berkelanjutan

Kegiatan sosialisasi mengenai konsep pariwisata dan konsep Eco-Geowisata Tim PHP2D menghadirkan narasumber. Dengan adanya sosialisasi ini diharapkan terjadinya perubahan perilaku masyarakat Desa Botubarani menjadi sadar sepenuhnya dan memiliki pengetahuan tentang pentingnya konsep pariwisata berkelanjutan agar warisan alam tetap terjaga khususnya unsur utama wisata desa yaitu situs Batu Berani. 


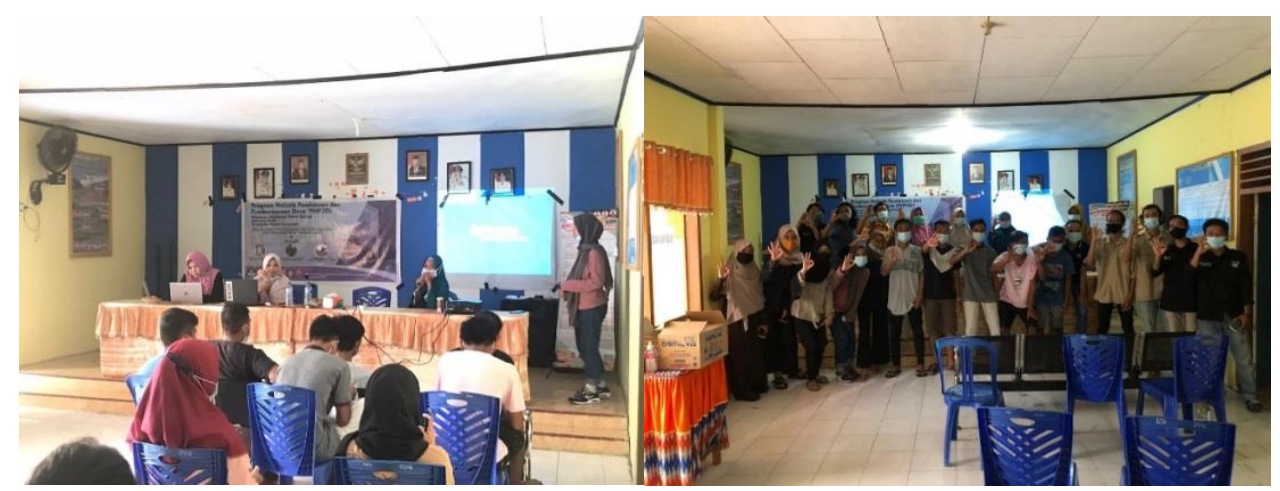

Gambar 4. Sosialisasi mengenai konsep pariwisata berkelanjutan dan konsep EcoGeowisata

3) Pelaksanaan

Tahap pelaksanaan PHP2D ini yaitu dengan melakukan pembersihan area lahan situs batuberani dan melakukan pembuatan fasilitas serta infrastruktur pada lokasi. Dalam pelaksanaan ini Tim PHP2D dibantu oleh mitra (Karang Taruna) dalam memperindah kawasan situs agar bernilai edukatif, nyaman, dan juga menarik.

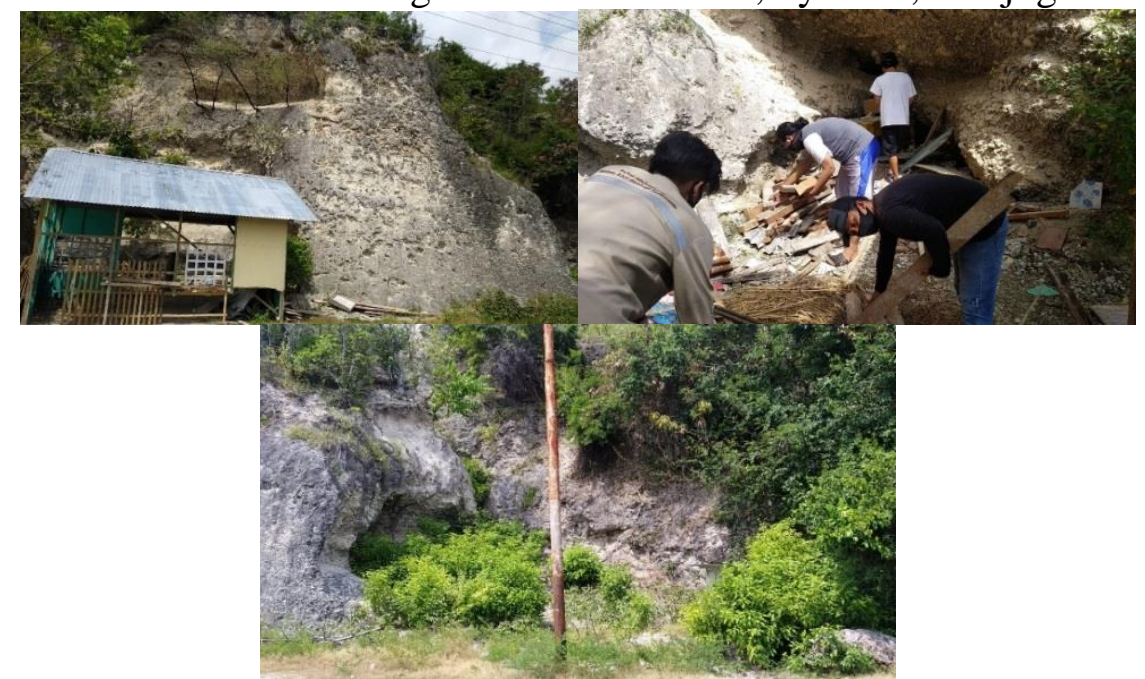

Gambar 5. Area Situs Batu Berani sebelum pelaksanan program

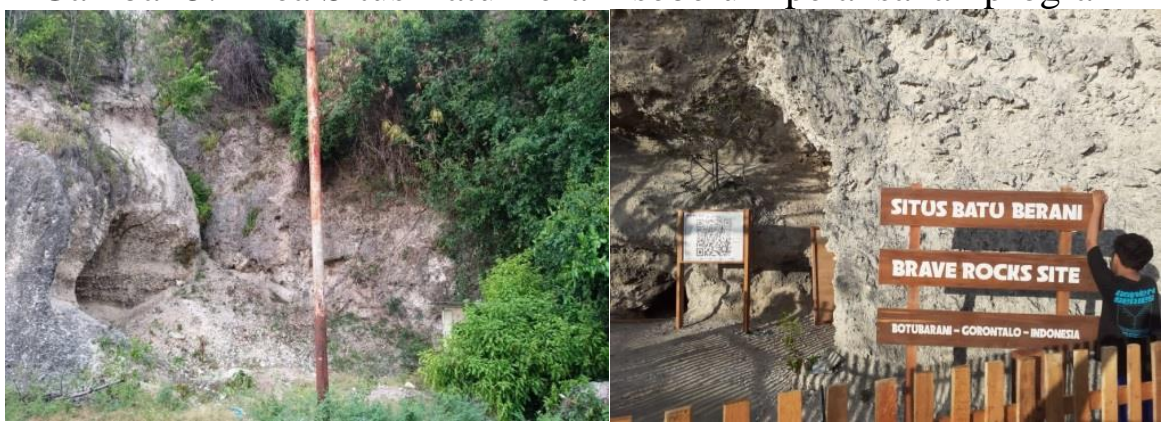

Gambar 6. Situs Batu Berani setelah pelaksanaan program

Tahap pelaksanaan PHP2D ini yaitu dengan melakukan pembersihan area lahan situs batuberani dan melakukan pembuatan fasilitas serta infrastruktur pada lokasi. Dalam pelaksanaan ini Tim PHP2D dibantu oleh mitra (Karang Taruna) dalam memperindah kawasan situs agar bernilai edukatif, nyaman, dan juga menarik. 
Tahapan selanjutnya yaitu dengan melakukan pembuatan infrastruktur yang akan menambah daya tarik wisata situs Batu Berani. Diantaranya pembuatan spot foto bernuansa bajak laut, QR Qodes, papan informasi, pagar pembatas yang bermanfaat dalam menunjang fasilitas di objek wisata tersebut. Dari pembuatan infrastruktur situs akan memberikan informasi.

a. Pembuatan Papan Informasi

Papan informasi merupakan satu dari sekian banyak fasilitas penunjang sarana kepariwisataan. Papan infromasi ini berisi informasi mengenai situs batu berani mulai dari sejarah penamaan Batu Berani, serta analisis megaskopis dan mikroskopis batuan. Dengan adanya informasi ini memberikan wawasan bagi wisatawan yang berkunjung ke Situs Batu Berani sehingga tidak hanya rekreasi tetapi wisatawan dapat menambah ilmu pengetahuan mereka.

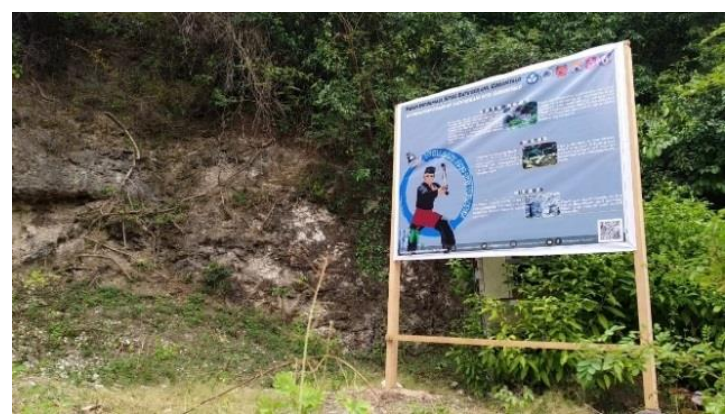

Gambar 7. Papan Informasi

b. Papan Nama Situs

Papan nama menjadi bagian penting sebagai informasi keberadaan situs Batu Berani. Maka dengan program PHP2D mahasiswa tim pelaksana dengan kelompok masyarakat sasaran (Karang Taruna dan POKDARWIS) merancang serta membuat papan nama Situs Batu Berani. Hal ini selain menambah infrastruktur keindahan tempat wisata, juga menjadi identitas dan center point dari keberadaan Situs Batu Berani. Pembuatan papan nama situs dibantu oleh masyarakat pengrajin kayu yang ada di Desa Botubarani.

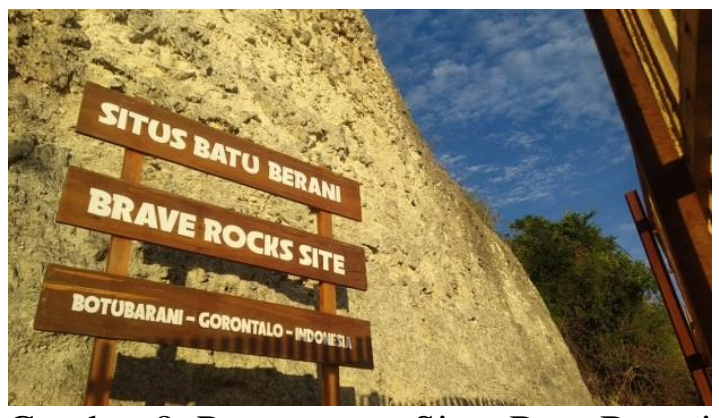

c. QR Qodes

Gambar 8. Papan nama Situs Batu Berani

Seiring berkembangnya teknologi ponsel cerdas, dalam mendapatkan kebaruan informasi. Pemasangan QR Qodes pada situs Batu Berani merupakan salah satu cara yang dilakukan tim pengabdian agar masyarakat dan wisatawan mendapatkan informasi yang lebih lengkap tentang situs Batu Berani. 
Pengunjung terbantu dengan QR Code dalam mengakses informasi (Dagan dkk, 2016) terkait situs Batu Berani.

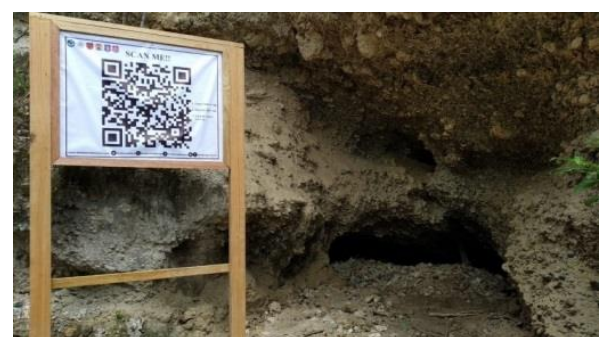

Gambar 9. QR Code pada Situs Batu Berani

d. Pagar Pembatas Situs

Untuk melindungi Kawasan situs dari potensi pengerusakan baik dari masyarakat maupu wisatawan yang berkunjung, maka pagar pembatas ini sangat membantu untuk mencegah adanya hal yang tidak diinginkan, agar situs ini dapat terjaga keberadaannya.

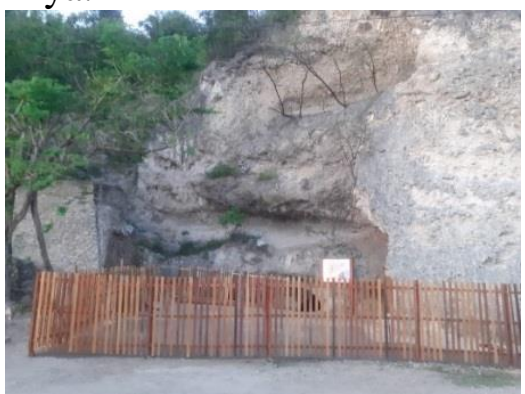

Gambar 10. Pagar pembatas situs

e. Icon Perahu

Pembuatan Icon perahu dimaksudkan untuk memberikan nuansa bajak laut karena situs Batu Berani ini mempunyai cerita sejarah mengenai penguburan mayat-mayat bajak laut yang dikubur oleh ti Barani di Goa ini. Daya Tarik dari situs ini selain bersifat edukatif, juga memiliki nilai sejarah dari penamaan Desa Botubarani.

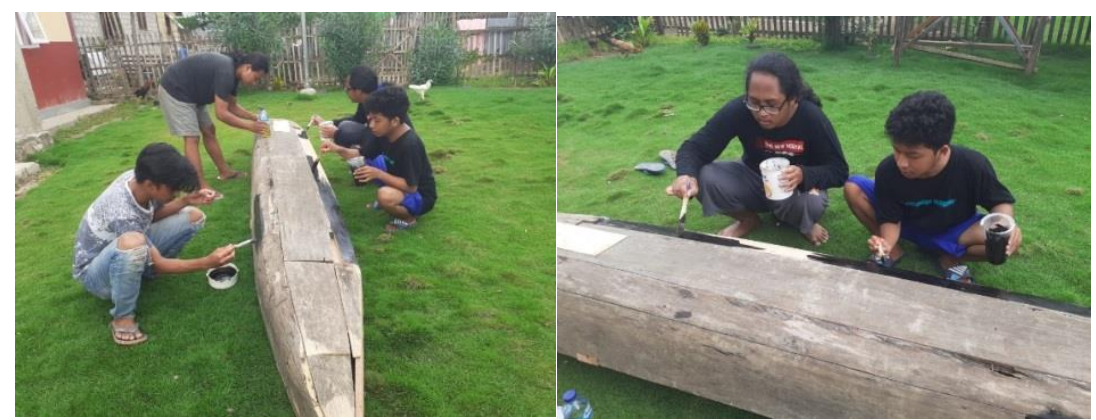

Gambar 11. Pewarnaan Icon perahu

4) Workshop dan pelatihan online marketing 
Pelatihan online marketing campaign dilaksanakan di cottage pangkalan III wisata Hiu Paus yang diikuti oleh para pemuda karang taruna. Pelatihan yang diberikan mengenai cara mempromosikan objek wisata melalui media-media online seperti web, media sosial seperti Instagram, Facebook dan YouTube.

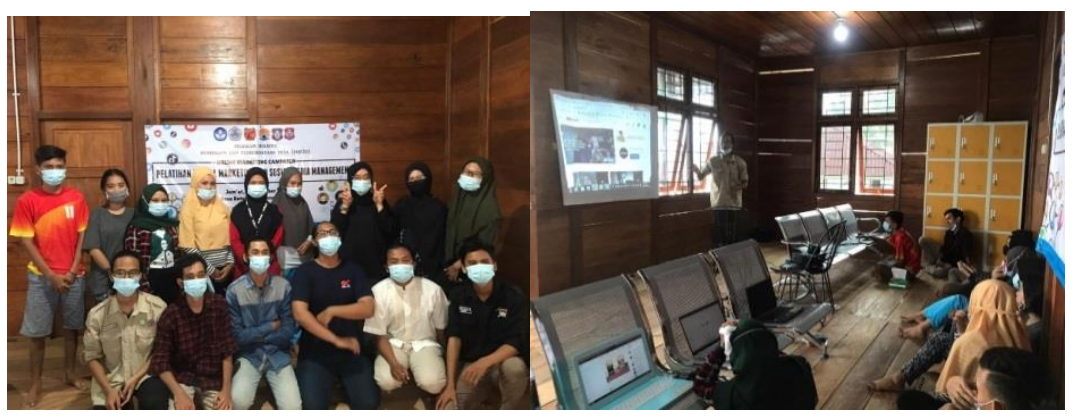

Gambar 12. Pelatihan Online Marketing dan Social Media Management

\section{5) Mentoring}

Kegiatan mentoring tim pelaksana kepada kelompok sasaran (Karang Taruna) dilakukan selama program PHP2D berlangsung, yaitu pada periode Agustus November 2020. Kegiatan mentoring dilakukan dengan memberi petunjuk tahapan demi tahapan dalam pengembangan Situs Batu Berani untuk menjadi sebuah geosite yang dikonservasi dan dapat mendatangkan keuntungan bagi masyarakat sekitar. Beberapa kendala yang dihadapi masyarakat dilaporkan serta dievaluasi dalam kegiatan mentoring.

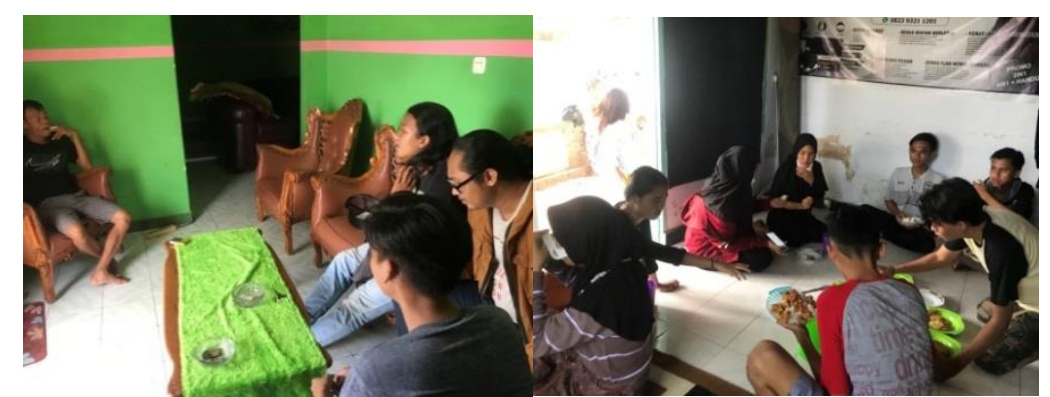

Gambar 13. Kegiatan mentoring tim PHP2D kepada masyarakat sasaran

Dalam kegiatan mentoring, partisipasi dan keaktifan masyarakat menjadi salah satu kunci keberhasilan pembimbingan. Partisipasi masyarakat sasaran ini diwujudkan dalam bentuk diskusi dan pengembangan kreativitas.

\section{PENUTUP}

Secara keseluruhan pengembangan Situs Batu Berani pada Program Holistik Pembinaan dan Pemberdayaan Desa (PHP2D) yang melibatkan Karang Taruna berjalan dengan baik. Semangat masyarakat dalam mengikuti rangkaian kegiatan pelaksanaan program terlihat dari keseriusan dan kegigihan mereka dalam mengikuti sosialisasi dan pelatihan, mengerjakan pembuatan infrastruktur wisata serta kegiatam monitoring dari awal hingga akhir program PHP2D. Salah satu kendala yang dihadapi pada saat pelaksanaan program diantaranya adalah terbatasnya SDM dalam menerapkan konsep 
pariwisata berkelanjutan dan pengelolaan online marketing campaign pada Situs Batu Berani. Hal ini kemudian seiring waktu berjalan dapat teratasi dengan adanya beberapa kegiatan pemberdayaan seperti sosialisasi konsep pariwisata berkelanjutan, pelatihan online marketing campaign dan pendampingan atau mentoring selama program PHP2D.

Pelaksanaan pengembangan Situs Batu Berani telah menghasilkan luaran utama pada program PHP2D. Kegiatan pemberdayaan ini terbukti mampu meningkatan pengetahuan dan kemampuan masyarakat botubarani dalam mengelola tempat wisata yang ada. Situs Batu Barani di Desa Botubarani kemudian mulai diperhatikan oleh masyarakat sekitar dan mulai dikelola dengan memperhatikan keberlanjutan dari situs bersejarah ini. Kegiatan ini membantu dan menginspirasi remaja Karang Taruna mencintai dan menghargai budaya, unsur-unsur tradisional dan keanekaragaman alam dan hayati yang dimiliki di Desa Botubarani dan berpartisipasi mengembangkannya.

\section{UCAPAN TERIMA KASIH}

Penulis mengucapkan terima kasih kepada Ditjen BELMAWA DIKTI Kementerian Pendidikan Kebudayaan Riset dan Teknologi yang telah mendanai kegiatan Program Holistik Pembinaan dan Pemberdayaan Desa (PHP2D) serta Program Pengembangan Pemberdayaan Desa (P3D) yang dilaksanakan di Desa Botubarani. Sosialisasi konsep pariwisata berkelanjutan dan konsep eco-geowisata dalam kegiatan ini mendapat dukungan dari The Research Institute for Humanity and Nature (RIHN: a constituent member of NIHU), Project No.14200102.

\section{DAFTAR PUSTAKA}

Anugrah, K. 2018. Optimalisasi Usaha Kuliner di Obyek Wisata Hiu Paus Desa Botu Barani Kabupaten Bone Bolango, Gorontalo. Jurnal Pariwisata Pesona, 3(2), 191204. https://doi.org/10.26905/jpp.v3i2.2463.

Dagan, I. Binyamin, G. \& Eilam, A. 2016. Delivery of QR Codes to Cellurar Phones throught Data Embedding in Audio, International Conference on the Science of Electrical Engineering, DOI: 10.1109/ICSEE.2016.7806076.

Hermawan, H. 2017. Pengaruh Daya Tarik Wisata, Keselamatan dan Sarana Wisata Terhadap Kepuasan serta Dampaknya terhadap Loyalitas Wisatawan: Studi Community Based Tourism di Gunung Api Purba Nglanggeran. Wahana Informasi Pariwisata: Media Wisata, 15(1), 562-577.

Manyoe, I. N., Arifin, Y. I., Napu, S. S. S., \& Suma, M. D. 2021. Assessment of the values of science, education, tourism and the risk degradation of Pentadio geothermal areas to developing geotourism in the Limboto Lake Plain, Gorontalo. In Journal of Physics: Conference Series (Vol. 1968, No. 1, p. 012047). IOP Publishing.

Pradiatiningtyas, D., Studi, P., Akuntansi, K., \& Bandung, A. 2014. Pemasaran Online Melalui E-Tourism, Bauran Pemasaran Jasa Pariwisata dan Pemosisian untuk Promosi Pariwisata. V(2), 77-87.

Sharpley, R. 2000. Tourism and Sustainable Development: Exploring th Theoretical Divice. Journal of Sustainable Sustainable Tourism, VIII (1): 1-19

Suryadana, M. V. O. 2015. Pengantar Pemasaran Pariwisata. Bandung Indonesia: Alfabeta. 